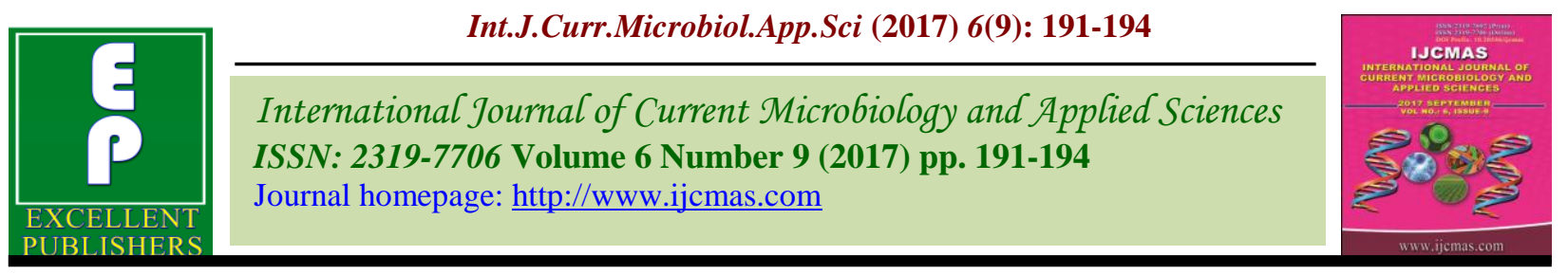

Original Research Article

https://doi.org/10.20546/ijcmas.2017.609.025

\title{
Technological Gap in Processing and Preservation of Fruits Perceived by Farm Women
}

\author{
Varsha Hada ${ }^{1}$ and Vishakha Bansal ${ }^{2 *}$ \\ ${ }^{1}$ College of Home Science, MPUAT, Udaipur, Rajasthan, India \\ ${ }^{2}$ AICRP - EECM, College of Home Science, MPUAT, Udaipur, Rajasthan, India \\ *Corresponding author
}

\section{A B S T R A C T}

\begin{tabular}{|l|}
\hline Ke y w or d s \\
Technological \\
gap, Rural women, \\
Processing and \\
Preservation. \\
\hline Article Info \\
\hline $\begin{array}{l}\text { Accepted: } \\
\text { 04 July 2017 } \\
\text { Available Online: } \\
\text { 10 September } 2017\end{array}$ \\
\hline
\end{tabular}

The objective of the present study was to identify the technological gap in knowledge perceived by rural women in processing and preservation of fruits of Udaipur District. The study was conducted in Badgaon and Girwa panchayat samities of Udaipur district of Rajasthan state. From each panchayat samiti, two villages were included in the study. The sample consisted of randomly selected 100 rural women, 25 from each village. Interview method was used for data collection. Frequency and percentage were used for analysis of data. Finding of the study reveals divulges that the overall technological gap of knowledge in fruit processing and preservation practices was 63.16 per cent which shows the average knowledge of the respondents in all the processing and preservation activities. Component wise technological gap focuses that highest gap was observed in the components storage 83.70 per cent, marketing 78 per cent, packaging 73.72 per cent and processing and preservation 70.68 per cent which were ranked I,II,III and IV respectively. Similarly, a wide knowledge gap was found in the components- grading 63.45 per cent and washing 56.75 per cent. Medium knowledge gap was found in the component fruit selection 29.66 per cent.

\section{Introduction}

India is known to be a fruit basket of the world. After china, India has been considered as the second largest producer of fruits and vegetables in the world with 74.877 million metric tonnes production of fruits and 146.554 million metric tonnes production of vegetables for the year 2010-11, as informed by the Minister of State for Food Processing Industries (www.blogspot.com). The total production of fruits and vegetables in the world is around 370 metric tonnes. But there is considerable gap between the gross production and net availability of fruits and vegetables due to heavy post-harvest losses.
Due to short life of horticultural crops, as much as 30-35 per cent of fruits and vegetables perish during harvest, storage, grading, transport, packaging and distribution, amounting to a revenue loss of Rs. 500 billion. In India only 2.2 per cent of fruits and vegetables are processed, whereas in countries like USA 65 per cent, China 23 per cent and Philippines 72 per cent are far ahead of India in reducing the wastage and enhancing the value addition and shelf life of the farm products. Hence there is a need for maximum commercial utilization of fruits and vegetables and to adopt production and 
marketing activities to the requirements of the world market and to cater to domestic demand which over the past year, has been increasing because of various socio-economic factors. If the nutritive value of the processed food products could be maintained, this sector will emerge as a major value-added food industry.

Rural women form the most momentous productive work force in the economy of majority of the developing nations, including India. Historians believe that it is women who first domesticated the crop and initiated the art and science of farming. Women play an important role in agriculture and they are moulder and builder of any nation's destiny.

The rural women are very active in cultivation, dairy, fisheries, crop processing and other allied areas. Maheshwari (2001) unveiled that almost 70 per cent of the total population and 84 per cent of the economically active women are involved in agriculture and make up to 46 per cent of the agricultural work force. The result of the research studies indicates that despite the dominance of the labour force, women in India are still facing extreme disadvantages; they have less knowledge, limited access to technology, low capital, low facilities etc. Thus, it is imperative that women should be trained in agriculture and allied areas.

\section{Materials and Methods}

The study was conducted in Udaipur district of Rajasthan state. There are number of fruits grown in Udaipur district like- Mango, Lime, Banana, Papaya, Guava and Aonla. Out of which three fruits having highest production were selected purposively for the present study. Udaipur district consists of seventeen panchayat samities out of which two panchayat samities- Badgaon and Girwa were selected purposively on the basis of highest production of the selected fruits. A list of villages was prepared and two villages each from both the panchayat samities namely Badi and Madar from Badgaon panchayat samiti and Sesarma and Bujda from Girwa panchayat samiti were selected for the present study. A village wise list of rural women, who were growing one of the selected fruit in their orchards, was prepared. A sample of 25 rural women was randomly selected from each village making a total sample of 100 rural women from four villages. Data were collected with the help of interview schedule. Frequency, percentage and Mean Weighted Score were used for analysis of the data.

\section{Results and Discussion}

Technological needs or gap were identified on the basis of knowledge of the respondents regarding different fruit processing and preservation activities. In order to know the aspects in which knowledge of the farm women was lacking, technological needs or gaps were identified on the basis of MPS calculated for knowledge of the respondents in different aspects of fruit processing and preservation practices. Technological needs of the respondents in different aspects of fruit processing and preservation is depicted in table 1.

Cursory look at table 1 divulges that the overall knowledge gap in fruit processing and preservation practices was 63.16 per cent which shows the average knowledge of the respondents in all the processing and preservation activities. Component wise knowledge gap focuses that highest gap was observed in the components storage 83.70 per cent, marketing 78 per cent, packaging 73.72 per cent and processing and preservation 70.68 per cent which were ranked I,II,III and IV respectively.

Similarly, a wide knowledge gap was found in the components- grading 63.45 per cent 
and washing 56.75 per cent. Medium knowledge gap was found in the component fruit selection 29.66 per cent. This was due to the reason that women were participating in these activities either independently or with male members so they had knowledge regarding these aspects.

Based on the findings it can be concluded that wide knowledge gap exists in almost all the aspects of fruit processing and preservation practices. This was due to non-participation of women in fruit processing and preservation practices of fruits as the activities are highly technical in nature and were mostly performed by male members of the family. Besides this the women did not have any access to the information related to fruit processing and preservation practices of fruits and none of them attended any training programme related to the aspect. Illiteracy of women also hurdled in information empowerment of women farmers. The findings also highlights that handling of the produce after harvesting is the sole responsibility of women, yet due to lack of knowledge regarding processing and preservation of fruits, women use to sell the product as such in the market and get less return. If women are given training in value addition of fruits like preparation of murrabba, chutney, squash, pickle etc., they can fetch good price of the produce. Hence, efforts should be made to provide trainings to the women in recommended fruit processing and preservation techniques.

Table.1 Knowledge gap of the respondents in different fruit processing and preservation practices

\begin{tabular}{|l|l|l|l|l|}
\hline \multirow{2}{*}{ S. No. } & \multirow{2}{*}{ Components } & \multicolumn{3}{l|}{ Knowledge } \\
\cline { 3 - 5 } & & MPS & Gap (\%) & Rank \\
\hline 1 & Fruit selection & 70.66 & 29.34 & VII \\
\hline 2 & Washing & 56.75 & 43.25 & VI \\
\hline 3 & Grading & 36.55 & 63.45 & V \\
\hline 4 & Processing and preservation & 29.35 & 70.68 & IV \\
\hline 5 & Packaging & 26.28 & 73.72 & III \\
\hline 6 & Storage & 16.30 & 83.70 & I \\
\hline 7 & Marketing & 22 & 78 & II \\
\hline Overall Knowledge Gap & $63.16 \%$ & \\
\hline
\end{tabular}

Table.2 Distribution of the respondents by their overall knowledge about fruits Processing and preservation activities

\begin{tabular}{|c|c|c|}
\hline & & $\mathrm{N}=100$ \\
\hline S. No. & Knowledge Category & $\mathbf{f} / \%$ \\
\hline 1. & Poor & 63 \\
\hline 2. & Average & 35 \\
\hline 3. & Good & 2 \\
\hline
\end{tabular}

Mean percent knowledge score: 17.29

\section{Overall knowledge}

To know the knowledge level of the respondents about fruits processing and preservation practices, they were grouped in three categories of knowledge namely poor, average and good on the basis of their mean percent scores. 
Perusal of the table 2 indicates that the respondents had poor knowledge about processing and preservation techniques of fruits as overall mean per cent score of knowledge was found to be 17.29. Distribution of the respondents in different categories of knowledge depicts that majority of them 63 per cent were in the category of poor knowledge whereas, 35 per cent belonged to the average knowledge category and only 2 per cent of the respondent had good knowledge regarding fruit processing and preservation practices.

Dave (2011) in their study on "Impact of Selected Horticultural Technologies Promoted under National Agricultural Innovation Project on Tribal Women of Banwara District" found that farm women possessed average to good knowledge in all the components of selected horticultural technologies as compared to nonparticipants.

Similarly, Dubey (2013) in her study on 'Technological needs of farm women in cultivation and post-harvest practices of Ber (Ziziphus mauritana) in Bharatpur District (Rajasthan)' stated that respondents had poor knowledge about improved cultivation and post-harvest practices of ber with overall mean per cent score of 14.36 .

Based on the findings it can be concluded that wide knowledge gap exists in almost all the aspects of fruit processing and preservation practices. This was due to non-participation of women in fruit processing and preservation practices of fruits as the activities are highly technical in nature and were mostly performed by male members of the family. Besides this the women did not have any access to the information related to fruit processing and preservation practices of fruits and none of them attended any training programme related to the aspect. Illiteracy of women also hurdled in information empowerment of women farmers.

The findings also highlights that handling of the produce after harvesting is the sole responsibility of women, yet due to lack of knowledge regarding processing and preservation of fruits, women use to sell the product as such in the market and get less return. If women are given training in value addition of fruits like preparation of murrabba, chutney, squash, pickle etc., they can fetch good price of the produce. Hence, efforts should be made to provide trainings to the women in recommended fruit processing and preservation techniques.

\section{References}

Maheshwari, R., 2001. Occupational health hazards experienced by farm women, Rajasthan, India. M.Sc. Thesis, Rajasthan Agricultural University, Udaipur, Rajasthan. Retried from www.blogspot. com on $10 / 7 / 2017$.

Dave, R., 2011. Impact of selected horticultural technologies promoted under National agricultural innovation project on tribal women of Banswara district, Rajasthan, India. M.Sc. Thesis, Maharana Pratap University of Agriculture and Technology, Udaipur, Rajasthan.

Dubey, N., 2013. Technological needs of farm women in cultivation and post-harvest practices of Ber (Ziziphus mauriana) in Bharatpur district (Rajasthan), Rajasthan, India. M.Sc. Thesis, Maharana Pratap University of Agriculture and Technology, Udaipur, Rajasthan.

\section{How to cite this article:}

Varsha Hada and Vishakha Bansal. 2017. Technological Gap in Processing and Preservation of Fruits Perceived by Farm Women. Int.J.Curr.Microbiol.App.Sci. 6(9): 191-194. doi: https://doi.org/10.20546/ijcmas.2017.609.025 